Sustainable Water Management in the Baltic Sea Region in an Enlarged EU

\section{The Water Framework Directive could be the Key}

\begin{abstract}
Die Wasserrahmenrichtlinie ist eine der wichtigsten neven EU-Richtlinien im Hinblick auf eine nachhaltige Entwicklung. Auch in den Beitrittsländern sind die Vorbereitungen zur Übernahme in vollem Gange. Da das Management von Wasserressourcen in unmittelbarem Zusammenhang mit Fragen der Landnutzung und der allgemeinen wirtschaftlichen Entwicklung steht, sind für eine erfolgreiche Umsetzung jedoch noch zahlreiche finanzielle und institutionelle Hindernisse zu überwinden.
\end{abstract}

$\mathrm{T}$ Von Henrik Dissing he EU enlargement process takes place parallel with the strive for sustainability as outlined in the Amsterdam Treaty and the EU sustainability strategy. An evident indicator for sustainable development in the Baltic Sea region - home to more than 80 million people - is the environmental quality of the Baltic Sea itself. High concentrations of nitrate and phosphate causing eutrophication, a severe oxygen deficit in one third of the sea bottom, and a negative impact on fish stocks are today present in the Baltic Sea and coastal habitats are under strong pressure in most parts of the region. Despite substantial investments during the previous decade to address point-source problems, further investments are yet to be made. The difficult challenge, however, lies in dealing with non-point source pollution from households, agriculture, small- and medium sized companies and dispersed settlements.

Almost all pollution problems in the Baltic Sea originate from land-based sources. This article is based on the assumption, that water management - if seen in a sustainable development context - cannot be seen separately neither from landscape planning as such nor from economic development.

In combination, the ecosystem-based concepts of the EU Water Framework Directive (WFD), the Habitat Directive (HD) and the Integrated Coastal Zone Management Strategy (ICZM) do offer a promising ecological foundation for sustainable development (1). They have been developed with the overall aim of securing our life support systems: well-functioning water cycles, securing of nature's functionalities and ecological processes and balancing coastal zone ecosystem dynamics with the economic development interests. Further, they are based on:
Using the ecosystem boundaries as the framework for planning and management,

- holistic and integrated approaches linking e.g. water use and land-use,

- capacity building at regional and local administrative levels, and

- comprehensive public participation. the realisation of these potentials in the Candidate Countries (CCs).

\section{Lessons learned from the ICZM process}

In order to assess the readiness of the CCs to embark on sustainable development, a review of the experiences of the Integrated Coastal Zone Management process in the Baltic Sea region is relevant. During 1995-1999, a number of demonstration projects took place in some of the largest coastal ecosystems in the Southern and Eastern part of the region within the so-called HELCOM PITF MLW project (2). A range of important lessons learned could be obtained:

- Difficulties for the involved authorities to undertake cross-sector co-operation,

- lack of experience in public participation as well as lack of strong local NGOs,

- integration of development and environment interests difficult to comprehend,

- land-use planning and landscape management without sufficient legislative structures,

- big difficulties in addressing upstream factors when dealing with downstream problems, and

- substantial lack of resources and competencies at local and regional authorities' level.

Overall, a range of constraints prevented proper implementation of ICZM as a concept for sustainable development in these coastal ecosystems.
This article will mainly try to identify barriers to

\section{Preparing for the Water Frame- work Directive}

The WFD provides three major challenges: administrative, technical and process management. There seems to be little doubt that the CCs will have their administrative arrangements in place by end of 2003, at a level fully comparable to the member states. In the following, the preparedness of the CCs with regard to the two others is discussed. The WFD outlines a number of obligations, including:

- One integrated plan for the entire river basin district comprising all aspects of water management, setting water quality targets for each water body,

- a vast number of technical specifications being mandatory for monitoring systems, characterisation and classification of water bodies, identification of heavily modified water bodies etc.,

- a range of comprehensive analysis will have to be undertaken by end of 2004, a monitoring system will have to be set up by end of 2006, and different stages of the plan itself have to be issued for public consultation subsequently,

- achievement of ,good ecological status“ for all water bodies by 2015 (3);

- active stakeholder involvement.

Other measures than the end-of-pipe, hard-engineering ones will have to be applied through active involvement of the users and polluters. Results will have to be achieved at the source, which implies mobilising the innovative capacity of the corporate sector in terms of improved environmentally friendly design of devices and optimisation of production patterns with regard to resource use efficiency. Further, water uses at household levels have to be considered as well. All these technical aspects of WFD will challenge the CCs dramatically.

\section{Also Institutional Challenges}

During the previous decade the Candidate Countries have undertaken a tremendous restructuring effort within the public administration at national level. Still, a variety of changes has to be made to make these institutions able to facilitate a process towards sustainability. No doubt, institutional constraints will hamper the process of change.

The institutional challenge is preset by so-called system inertia: the mode of operation, mechanisms and institutional cultures, which inevitably follows setting up whatever type of structure with a certain mandate and self-understanding. Two key conclusions:

1. Sustained participation in development demands transformations in three domains: methods and procedures; institutional cultures; and 
personal behaviour and attitudes. All three are needed. Each reinforces the others. Each presents points of entry for change.

2. Of these, personal behaviour and attitudes are crucial. Participation is about how people interact. Dominating behaviour inhibits participation. Democratic behaviour to enable and empower encourages it. For those with power and authority to adopt non-dominating, empowering behaviour almost entails personal change.

Public Participation is a cornerstone of the WFD, as outlined prominently in its preamble. But active involvement of the public will easily require additional funds.

Despite the fact, that virtually all actors on the ,water scene" recognise the challenges imposed by the WFD and the related needs for increasing staff numbers and capacity building, not least at local and regional level, additional budget allocations may be scarce in the CC. Thus, the institutional challenges in the context of WFD implementation seem to pose a tremendous problem for the CCs.

\section{- Environmental Impact of Accession}

Which will be the likely effects of accession on the environmental state of central and eastern European river basins and the Baltic Sea? This question is indeed complicated to answer. The observations presented below call for concern: - Implementation of SAPARD and ISPA programs during the accession process was in many of the CCs not accompanied by a priority given to environmental protection, strengthening of the ecological infrastructure, e.g. wetlands restoration, or substantial investments in environmentally-friendly farming.

- Implementation of the Habitat Directive has been in most CCs ,according to the book“, i.e. formalities are in place in terms of delimitation of areas etc.; however, virtually no steps were taken towards implementation of the important article 10 of the HD, which focuses on establishing ecological corridors.

- Several large-scale construction works in the CCs have been planned or even implemented without proper Environmental Impact Assessments.

Altogether, this signals that traditional development perceptions prevail, and that effects on the environmental state of river basins and the Baltic Sea will not be given priority.

\section{International and Regional Co-operation}

During the last couple of decades international cooperation in the Baltic Sea Region has taken place in a variety of examples (4). Following enlargement, a structure like the Helsinki Commission (HELCOM) and EU programs will be the most important. One may say that the recent approach of HELCOM until now has not secured this institution to remain a strong driver for environment protection in the region - and it has never been a driver for sustainable development. Rather, the last couple of years have seen diminishing interest from most of the contracting parties. If international cooperation through HELCOM is anticipated to make a difference, it has to be reformed to become a strong, comprehensive program based on sincere, high-level commitment which should be able to:

- Within the region, to secure mutual agreement on prioritising coastal and marine environmental problems, e.g. when elaborating river basin management plans,

- secure joint acceptance of the root-causes of the problems, and dividing responsibilities for solutions among the countries,

- constitute a dynamic framework for exchange of experiences, and for innovative, solution-oriented projects, based on participation of all relevant actors,

- unanimously call for a reform of the Common Agricultural Policy in order to reduce environmentally perverse subsidies, connect funding flows to support e.g. wetlands restoration.

Eight out of nine riparian countries in the Baltic Sea region will become $\mathrm{EU}$ members and then be subject to the same standards, legislation, structures and priorities. No doubt, this is highly valuable for a joint, international effort in the region.

If the $\mathrm{EU}$ is to be the body making the difference, it has to reform its support programs. Currently, the subsidies for agricultural production represent a huge threat for the Baltic Sea environment, at the same time support programs do not prioritise ecological landscape development, e.g. wetlands restoration, or environmentally-friendly agricultural production. To put it simple, it does not yet ,pay off “ for rural communities to protect the environment (5).

\section{Conclusion}

WFD, HD and ICZM are very strong concepts, but also very advanced ones requiring a lot of capacity at local and regional level in terms of resources and skills, in-depth understanding of and commitment to sustainable development mechanisms. The ,old“ sector-based, vertical-oriented administrative systems, which today prevail all over the Baltic Sea region, constitute a strong barrier for sustainable development.
Will there be staff resources set aside for development and implementation of a coherent landscape structure with adequate space for nature and its self-generating features? Will well-functioning ecosystems be seen as long-term pre-conditions for sustainable development? Quite a lot, regrettably, still points in the direction of negative answers to these questions. In many ways, the CCs are on a good track and a big effort has already been put into the implementation of WFD, however a range of constraints will probably hamper the process. It is therefore crucial that the EU Commission sends a strong and unmistakably signal that full WFD implementation is expected and that the goals in terms of water quality by 2015 are to be achieved. Financing programs for WFD implementation are needed, particularly emphasising its ecological aspects.

\section{References}

(1) See http://europa.eu.int/comm/environment/... water/water-framework/overview.html, nature/habdirde. htm, iczm/home.htm

(2) Helsinki Commission - Programme Implementation Task Force - Management Plans for Coastal Lagoons and Wetlands, see: www.helcom.fi. The regions covered are Väinameri region (Matsalu Bay and Käina Bay) in Estonia, Lake Engure in Latvia, Kursiu Lagoon shared between Lithuania and Russia, Vistula/Kaliningrad Lagoon shared between Russia and Poland, and Oder/Odra Lagoon shared between Poland and Germany.

(3) For more details on the WFD, see the special issue of Ökologisches Wirtschaften No. 2/2002.

(4) Besides HELCOM, for example several projects in the framework of the UN Economic Commission for Europe, conduct of the Miedzyzdroje Conference in 2002 (www.unece. org/env/water) or in the Baltic Eutrophication Regional Network (BERNET): co-operation among 7 countries focusing on eutrophication (www.bernet.org).

(5) See Dissing, H.: Elaboration of a Business Model for Sustainable Development in Rural Areas, WWF 2002 (download: http://europa.eu.int/comm/environment/governance/denmark_conference_papers.htm); and Dissing, H.: Does Nature Pay Off?, WWF 2002.

\section{Der Autor}

Henrik Dissing ist Mitglied des International Committee von Birdlife Denmark.

Kontakt: Birdlife Denmark, Vesterbrogade 140,

DK-1620 Copenhagen V, Denmark. Tel. 0045-33662899, Fax-7116,E-Mail: hd@mof.kk.dk 
(c) 20I0 Authors; licensee IÖW and oekom verlag. This is an article distributed under the terms of the Creative Commons Attribution Non-Commercial No Derivates License (http://creativecommons.org/licenses/by-nc-nd/3.o/), which permits unrestricted use, distribution, and reproduction in any medium, provided the original work is properly cited. 